\title{
A MULTI-PARAMETER EVALUATION OF PARALYMPIC SWIMMERS IN THE TRAINING CYCLE BEFORE 2016 PARALYMPIC GAMES
}

original paper

( ) University School of Physical Education in Wroclaw

DOI: https://doi.org/10.5114/hm.2020.91350

\section{JOÃO PAULO PEREIRA ROSA ${ }^{1,2}$, ANDRESSA SILVA ${ }^{1,2}$, DAYANE FERREIRA RODRIGUES ${ }^{1,2}$, RUI MENSLIN ${ }^{2,3}$, LEONARDO TOMASELLO ARAÚJO ${ }^{2}$, EDUARDO DA SILVA ALVES ${ }^{1,4}$, ROBERTO VITAL ${ }^{2}$, MARCO TULIO DE MELLO ${ }^{1,2}$}

${ }^{1}$ Escola de Educação Física, Fisioterapia e Terapia Ocupacional, Universidade Federal de Minas Gerais, Belo Horizonte, Brazil

${ }^{2}$ Comitê Paralímpico Brasileiro, Academia Paralímpica Brasileira, Brasília, Brazil

${ }^{3}$ Pontifícia Universidade Católica do Paraná, Curitiba, Brazil

${ }^{4}$ Universidade Estadual de Santa Cruz, Ilhéus, Brazil

\section{ABSTRACT}

Purpose. Paralympic athletes need physical, technical, and psychological training. The study aim was to monitor and compare multi-parameter variables during Paralympic swimmers' training cycle before Rio 2016 Paralympic Games.

Methods. Internal training load, motivation levels, mood states, stress, and recovery were measured at 3 testing times (T1, T2, T3) in 11 Paralympic swimmers. Friedman and Wilcoxon post-hoc tests served to verify differences $(p \leq 0.05)$.

Results. No significant differences occurred in motivation and mood states; however, the athletes' mood states followed the 'iceberg mood profile'. In sources and symptoms of stress, a difference existed in the number of 'worse than normal' responses $(p=0.03)$ in T1 $>\mathrm{T} 3(p=0.05)$ and T2>T3 $(p=0.05)$. Considering the training load, there was a difference in total internal training load $(p=0.02)$, with T1 showing greater values than T3 $(p=0.02)$ and T2>T3 $(p=0.02)$. The questionnaire to measure the recovery-stress status presented significant differences in conflicts/pressure subscales $(p=0.01)$ in T1>T2 $(p=0.03)$ and T1>T3 $(p<0.01)$, and in fatigue $(p<0.01)$ in T1>T2 $(p=0.05)$ and T1>T3 $(p=0.01)$.

Conclusions. Internal training load decreased from T1 to T3; lowest stress symptoms were observed in T3 with the lowest internal load, and scales of conflicts/pressure and fatigue were highest in T1. Monitoring multi-parameter data in the training cycle may explain the psychobiological aspects of Paralympic swimmers and provide important information for coaches and athletes to meet the specific demands of impaired athletes.

Key words: disability sports, Paralympic, testing, training, motivation

\section{Introduction}

Para-swimming is a popular sport for athletes with physical, visual, or intellectual impairments, to be considered a viable option for specific health conditions, since it requires the use of little equipment and only some adaptations in amateur level competitions up to the Paralympic level [1]. To ensure fair and equal competition, para-swimmers are classified depending on the impact of their impairment on the 4 swimming strokes. There are 10 different sports classes for athletes with physical impairment (numbered 1-10), and 9 sports classes for the breaststroke swimming style (SB1-SB9). A lower number indicates a more severe activity limitation than a higher number. Swimmers with visual impairments compete in 3 sports classes (11-13). Class S14 includes swimmers with intellectual impairments [2].

Paralympic swimming is increasingly popular [3], and the monitoring of training load constitutes a key component to understand training responses and changes in performance; traditional load units relate to either external or internal training load.

As a parameter to quantify internal training load

Correspondence address: Marco Túlio de Mello, Universidade Federal de Minas Gerais, Av. Presidente Carlos Luz, 4664, Pampulha, CEP 31.310.250 Belo Horizonte, MG, Brazil, e-mail: tmello@demello.net.br

Received: February 22, 2019

Accepted for publication: October 9, 2019

Citation: Rosa JPP, Silva A, Rodrigues DF, Menslin R, Araújo LT, Alves ES, Vital R, de Mello MT. A Multi-parameter evaluation of paralympic swimmers in the training cycle before 2016 paralympic games. Hum Mov. 2020;21(3):90-99; doi: https://doi.org/10.5114/hm.2020.91350. 
on the basis of psychobiological changes, the rating of perceived exertion (RPE) refers specifically to the feeling that an athlete retrospectively provides regarding their perceived effort after training or competition [4]; it is considered a very useful psychobiological variable to quantify the internal training load in sports training.

The stress associated with the training process may cause effects on important behavioural factors. Athletes with impairments may have to overcome barriers to training, and the impairment itself can lead to high levels of anxiety and insecurity in the face of certain situations, arising both from the conditions of daily life and from the demands of the sport [5].

Under these conditions, a negative training state may occur by an imbalance between stress (training and non-training) and recovery, leading to the overtraining syndrome [6]. Among the overtraining symptoms, athlete's mood is considered a decisive factor in sports performance and the evaluation of mood states can help in identifying and directing interventions to avoid overtraining syndrome [6].

To seek better results, athletes and coaches have to go beyond physical preparation, investigating other factors related to sports performance. As part of the training process in Paralympic athletes, training mental skills for sports, like motivational strategies, is used by the coach individually or collectively, which leads to increased confidence and mental activation of the athletes [7].

Among these factors, motivation is characterized as an active, intentional and goal-directed process, which depends on the interaction of intrinsic (e.g. enjoyment) and extrinsic (e.g. environmental) aspects and has a certain intensity, direction, and persistence to seek success and avoid failure [8]. It is a contributing element to achieve success in sports competitions. In Paralympic athletes, the main motive for sports practice is the competition and the desire to overcome limits [9].

There are several theories to elucidate motivation and its relation to human behaviour. The self-determination theory [10] regards human personality and motivation, focusing on the psychological needs and contextual conditions conducive to motivation, social functioning, and personal well-being. In this perspective, motivation is described as a multidimensional model that can reflect several aspects determined by the intrinsic and extrinsic motivation [10].

Although motivation in sport is considered as a complex and latent variable, self-determined motivation has been shown to be associated with higher levels of performance [11]. In contrast, low levels of motivation appear to complicate a successful sports career in the sense of sport persistence and dropout or a lower level of performance in sports [11].

Athletes in highly competitive levels of sport may experience decreases in their intrinsic motivation because of different factors, such as increased demands in training, experience of continuous injuries, or suffering pressure from coaches, family members, and/or supporters [12].

Therefore, the objectives of this study were to monitor and compare the multi-parameter variables (internal training load, motivation levels, mood states, stress, and recovery) during the training cycle of Paralympic swimmers before the Rio 2016 Paralympic Games.

\section{Material and methods}

\section{Experimental design}

The data were collected during three Weeks of Evaluation and Training conducted by the Brazilian Paralympic Committee during the cycle of training for the Rio 2016 Paralympic Games. Testing time 1 (T1) was 7 months before, testing time 2 (T2) 4 months before, and testing time 3 (T3) 1 week prior to the Paralympic Games. A general training plan was delineated by the coaches and considered the periodization cycle proposed to Paralympic swimmers; T1, T2, and T3 corresponded to the general/specific preparation, pre-competitive preparation, and tapering, respectively. No intervention was involved, this being a totally observational study. The training programs were not altered or adapted by the members of the Brazilian Paralympic swimming team as a result of the data collected.

\section{Participants}

Overall, 11 Paralympic male swimmers from the Brazilian swimming team participated in this study. The athletes were selected by the national swimming competitions to make up the national team. At the T1, $\mathrm{T} 2$, and T3 time points, the para-swimmers were members of the same team, which were trained by the same staff and followed the stage of the training program together.

The athlete's age (mean + standard deviation) was $22.7 \pm 5.0$ years, and sports experience equalled $7.2 \pm$ 2.9 years. Para-swimmers are classified depending on the impact of their impairment, with the letter S identifying the modality of swimming. In the present study, the participants (in accordance with the paraswimming classification) were characterized by visual impairment (3 athletes: 1 with S11, 2 with S13), intel- 
lectual impairment (1 athlete, with S14), poliomyelitis (3 athletes: 1 with S7, 1 with S9, 1 with S10), amputation (3 athletes: 1 with S6, 2 with S9), and myelomeningocele (1 athlete, with S6).

\section{Procedures}

For the variables listed below, data collection was performed with each participant individually in the 3 testing times (T1, T2, and T3).

\section{Internal training load}

Session RPE (sRPE) was assessed 30 minutes after the end of each training session during the data collection week (a total of 5 trainings per week). The athlete responded to the question 'How was your training session?' on a scale between 0 (rest condition) to 10 (greater physical effort) [13]. The sRPE consists of the multiplication of sRPE score (intensity) by training session duration expressed in minutes (volume), and the results must be expressed in arbitrary units (AU). Monotony, representing the training variation across the week (monotony $=$ mean sRPE divided by standard deviation), and the training strain, representing the magnitude effect and the load distribution from the week (training strain $=$ weekly sRPE multiplied by monotony), were also calculated.

\section{Motivation in sport}

To evaluate the motivation levels of the athletes, the Sport Motivation Scale (SMS) in its validated version for the Portuguese language was used [14]. The questionnaire consists of 28 items, scored in a 7-point Likert scale, which ranges from 1 (does not correspond at all) to 7 (corresponds exactly). Higher scores indicate a higher level of motivation, with the total score of 28 points being the maximum for each subscale. The following items describe the different levels of intrinsic and extrinsic motivation.

Intrinsic motivation:

- 'To know': personal factors linked to curiosity and seeking understanding variables related to sport (items 2, 4, 23, 27);

- 'To accomplish': personal factors linked to the enjoyment in pursuit of new skills in sport (items 8 , $12,15,20)$

- 'To experience stimulation': when an athlete seeks experiences in sport that can cause excitement, pleasure, and fun (items 1, 13, 18, 25).
Extrinsic motivation:

- 'External regulation': related to external factors such as medals, trophies, financial rewards, or status (items 6, 10, 16, 22);

- 'Introjected': internal pressures that the athlete can put on themselves when not achieving their best performance (items 9, 14, 21, 26);

- 'Identified': athletes who participate in sport to achieve their personal growth (items 7, 11, 17, 24);

Amotivation: there is no reason to continue practice in sport (items $3,5,19,28$ ).

The self-determination motivation was measured with an index which had been employed in a previous study [15], in accordance with the following formula:

$[2 \times(\mathrm{IM}$ toward knowledge + IM toward practice + IM toward stimulation) / $3+$ identified regulation]

$-[($ introjection + external regulation) $/$ $2+2 \times$ amotivation]

where IM denotes intrinsic motivation.

\section{Mood states}

The Brunel Mood Scale (BRUMS) in a version translated and validated for the Portuguese language [16] was used to evaluate the athletes' mood. It consists of 24 items to assess mood change in 6 dimensions: tension, depression, anger, vigour, fatigue, and confusion. The data were evaluated and interpreted in percentile scores. The most suitable profile for mood states is the 'iceberg profile,' in which vigour reaches above the $50^{\text {th }}$ percentile and the other variables remain below that percentile.

\section{Sources and symptoms of stress}

The Daily Analysis of Life Demands for Athletes (DALDA) in the version translated and validated for the Portuguese language was used [17]. The questionnaire has 2 parts, part A and part B, that represent stress sources and symptoms, respectively. The instrument requires the athlete to qualify the items in question as being 'worse than normal,' 'normal,' or 'better than normal'. The general score was calculated as the sum of stress sources and symptoms in both parts (A and B). The DALDA questionnaire was applied at the end of each training week, as described by Robson-Ansley et al. [18]. 


\section{Recovery-stress status}

The Portuguese version of the Recovery-Stress Questionnaire for Sport-76 (RESTQ-Sport) was used [19]. The RESTQ-Sport is a multidimensional questionnaire, has a heavier emphasis on recovery and goals of the athletic population. There are 19 scales (12 general and 7 sport-specific scales), each containing 4 items evaluated by a Likert numerical scale with values that vary from 0 to 6 points. In addition, it assesses both the stress state and recovery state of the athlete within the previous 3 days. Higher scores (values $>4$ ) are associated with stress and lower scores (values 0-2) are bound with recovery. Values between 2.01 and 3.99 correspond to a stressful event experienced by athletes and conditions related to the recovery process.

On the basis of the descriptive analysis to determine the levels of stress and recovery, a total recovery-stress state (TRSS) was obtained, from the mean scores of the recovery scales (items $8-12$ and items 16-19) minus the mean scores of the stress scales (items 1-7 and items 13-15). A lower number expresses higher stress and under-recovery state in athletes.

A training week consisted of 5 days. On the $1^{\text {st }}$ day, the SMS questionnaire was applied; on the $5^{\text {th }}$ day, the RESTQ-Sport, DALDA, and BRUMS questionnaires were completed. At the end of each training session (30 minutes after), sRPE was assessed.

\section{Statistical analysis}

The SPSS Statistics v21 software was used to analyse the data. The Shapiro-Wilk test was performed, and when the assumptions of normality were not assured, the Friedman test was used to verify differences in the continuous variables collected during the training weeks evaluated. The results were described in the form of a median, a robust indicator of central tendency, and less sensitive to extreme scores $\left(50^{\text {th }}\right.$ percentile), $25^{\text {th }}$ and $75^{\text {th }}$ percentiles. The Wilcoxon signed-rank test was used to determine in which $\mathrm{T}$ there was a difference. Correlations between the variables of interest (training load, number of 'worse than normal' responses in DALDA, SMS, BRUMS items, and 'General stress' in RESTQ-Sport) were analysed by using Spearman's correlation. The level of significance was set at $5 \%$.

\section{Ethical approval}

The research related to human use has complied with all the relevant national regulations and institu- tional policies, has followed the tenets of the Declaration of Helsinki, and has been approved by the Committee of Ethics in Research of Universidade Federal de Minas Gerais (44119515.6.0000.5149).

\section{Informed consent}

Informed consent has been obtained from all individuals included in this study.

\section{Results}

The monitoring outcomes for training load and the perception of stress sources and symptoms in Paralympic athletes during the training cycle before the Rio 2016 Paralympic Games are described in Table 1.

Regarding the training load monitoring, there were differences between the testing times for total weekly load $\left[\chi^{2}(2 . N=11)=7.18 ; p=0.02\right]$ with $\mathrm{T} 1>\mathrm{T} 3(p=$ $0.02)$ and T2>T3 $(p=0.02)$. The mean weekly load $\left[\chi^{2}(2 . N=11)=7.18 ; p=0.02\right]$, monotony $\left[\chi^{2}(2 . N=11)\right.$ $=16.70 ; p<0.01]$, and strain $\left[\chi^{2} 2(2 . N=11)=16.70\right.$; $p<0.01]$ were also significantly different. Differences between testing times were observed in the mean weekly load values: T1>T3 $(p=0.02)$ and T2>T3 $(p<$ $0.01)$, monotony: $\mathrm{T} 1>\mathrm{T} 3(p=0.01)$ and $\mathrm{T} 2>\mathrm{T} 3(p<0.01)$, and strain: T1>T3 $(p<0.01)$ and T2>T3 $(p<0.01)$.

For sources and symptoms of stress (DALDA questionnaire), there was no difference between the numbers of 'worse than normal,' 'normal,' and 'better than normal' responses in part A (stress sources). In part B (stress symptoms), there was a difference in the number of 'worse than normal' responses $\left[\chi^{2}(2 . N=11)=\right.$ $6.51 ; p=0.03$ ], highlighting that both $\mathrm{T} 1$ and $\mathrm{T} 2$ showed higher 'worse than normal' stress symptoms as compared with T3 (T1>T3, $p=0.05$; T2>T3, $p=0.05)$.

Table 2 presents the motivation levels and mood states in the Paralympic swimmers in the weeks of training aimed at the 2016 Paralympic Games. No significant differences were found between the evaluated testing times for particular motivation levels. Regarding mood states, no significant differences were observed between the testing times. However, as noted in Figure 1, athletes showed the 'iceberg profile' (visual representation of desirable emotional health status of athletes), reflecting low scores on negative scales (tension, depression, anger, fatigue, and confusion) and higher scores on the positive vigour scale.

The values of the RESTQ-Sport questionnaire subscales among the training tests evaluated are presented in Table 3. There were significant differences between testing times for conflicts/pressure subscales $\left[\chi^{2}(2 . N\right.$ $=11)=8.21 ; p=0.01]$ and fatigue $\left[\chi^{2}(2 . N=11)=10.65\right.$; 


\section{HUMAN MOVEMENT}

J.P.P. Rosa et al., Monitoring of Paralympic athletes

Table 1. Perceived training load (total and mean), monotony, strain, and stress sources and symptoms in the Paralympic swimmers during the testing times

\begin{tabular}{|c|c|c|c|c|c|c|c|c|c|c|}
\hline \multirow[b]{2}{*}{$\begin{array}{l}\text { Internal training } \\
\text { load }\end{array}$} & \multicolumn{2}{|r|}{$\mathrm{T} 1$} & \multicolumn{2}{|r|}{$\mathrm{T} 2$} & \multicolumn{2}{|r|}{ T3 } & \multirow[b]{2}{*}{$\begin{array}{c}\text { Friedman } \\
(p \text { value })\end{array}$} & \multicolumn{3}{|c|}{ Wilcoxon test } \\
\hline & Median & $(25-75 \%)$ & Median & $(25-75 \%)$ & Median & $(25-75 \%)$ & & $\begin{array}{l}\text { T1 } \\
\text { vs. } \\
\text { T2 }\end{array}$ & $\begin{array}{l}\text { T1 } \\
\text { vs. } \\
\text { T3 }\end{array}$ & $\begin{array}{l}\text { T2 } \\
\text { vs. } \\
\text { T3 }\end{array}$ \\
\hline sRPE (AU) & 6.4 & $(4.6-7.6)$ & 6.8 & $(6.4-7.6)$ & 4.0 & $(3.6-5.8)$ & $<0.01^{*}$ & 0.06 & $<0.01^{*}$ & $<0.01 *$ \\
\hline $\begin{array}{l}\text { Training session } \\
\text { duration (min) }\end{array}$ & 72 & $(72-75)$ & 74 & $(72-75)$ & 57 & $(50-64)$ & $0.01^{*}$ & 0.08 & $0.01 *$ & $0.01 *$ \\
\hline $\begin{array}{l}\text { Total weekly load } \\
\text { (AU) }\end{array}$ & 2385 & (1705-2790) & 2505 & $(2385-2790)$ & 1370 & $(1170-2200)$ & $0.02 *$ & 0.06 & $0.02^{*}$ & $<0.01 *$ \\
\hline $\begin{array}{l}\text { Mean weekly load } \\
\text { (AU) }\end{array}$ & 477 & $(341-558)$ & 501 & $(477-558)$ & 274 & $(234-440)$ & $0.02 *$ & 0.06 & $0.02^{*}$ & $<0.01 *$ \\
\hline Monotony & 3.07 & $(1.54-6.71)$ & 3.07 & $(1.91-6.71)$ & 1.45 & $(1.32-1.86)$ & $<0.01^{*}$ & 0.14 & $0.01 *$ & $<0.01^{*}$ \\
\hline Strain & 8569.0 & $\begin{array}{c}(2584.8- \\
19,145)\end{array}$ & 8569.0 & $\begin{array}{c}(4671.2- \\
19,145)\end{array}$ & 1963.2 & $\begin{array}{c}(1512.8- \\
4097.8)\end{array}$ & $<0.01^{*}$ & 0.14 & $<0.01^{*}$ & $<0.01 *$ \\
\hline \multicolumn{11}{|l|}{ DALDA } \\
\hline WTN (part A) & 1 & $(0-2)$ & 0 & $(0-2)$ & 1 & $(0-1)$ & 0.80 & - & - & - \\
\hline Normal (part A) & 6 & $(4-7)$ & 5 & $(3-7)$ & 6 & $(4-7)$ & 0.84 & - & - & - \\
\hline BTN (part A) & 2 & $(1-3)$ & 2 & $(1-4)$ & 1 & $(1-4)$ & 1.0 & - & - & - \\
\hline WTN (part B) & 4 & $(2-5)$ & 5 & $(1-6)$ & 1 & $(0-3)$ & $0.03 *$ & 0.81 & $0.05^{*}$ & $0.05^{*}$ \\
\hline Normal (part B) & 18 & $(14-19)$ & 17 & $(14-18)$ & 20 & $(16-22)$ & 0.40 & - & - & - \\
\hline BTN (part B) & 4 & $(2-5)$ & 4 & $(1-6)$ & 3 & $(2-4)$ & 0.97 & - & - & - \\
\hline
\end{tabular}

$\mathrm{T}$ - testing time, sRPE - session rating of perceived exertion, AU - arbitrary units, min - minutes,

DALDA - Daily Analysis of Life Demands for Athletes, WTN - worse than normal, BTN - better than normal ${ }^{*} p<0.05$

Table 2. Motivation levels and mood states of the Paralympic swimmers during the testing times

\begin{tabular}{|c|c|c|c|c|c|c|c|}
\hline \multirow{2}{*}{ Sport Motivation Scale } & \multicolumn{2}{|c|}{$\mathrm{T} 1$} & \multicolumn{2}{|c|}{$\mathrm{T} 2$} & \multicolumn{2}{|r|}{ T3 } & \multirow{2}{*}{$\begin{array}{l}\text { Friedman } \\
\text { ( } p \text { value) }\end{array}$} \\
\hline & Median & $25-75 \%$ & Median & $25-75 \%$ & Median & $25-75 \%$ & \\
\hline IM ‘to know’ & 5.75 & $(5.25-6.25)$ & 5.75 & $(5.50-6.25)$ & 6.00 & $(5.25-7.00)$ & 0.38 \\
\hline IM 'to accomplish' & 6.25 & $(6.00-6.75)$ & 6.25 & $(5.00-6.75)$ & 5.75 & $(5.50-7.00)$ & 0.69 \\
\hline IM 'to experience' & 6.25 & $(6.00-6.75)$ & 6.25 & $(5.25-6.50)$ & 6.00 & $(4.75-7.00)$ & 0.91 \\
\hline EM 'external regulation' & 3.75 & $(2.25-5.00)$ & 3.25 & $(2.25-4.25)$ & 3.50 & $(2.50-4.25)$ & 0.61 \\
\hline EM 'introjected' & 5.00 & $(2.25-5.75)$ & 4.00 & $(1.50-5.25)$ & 4.75 & $(1.50-6.00)$ & 0.13 \\
\hline EM 'identified' & 3.75 & $(3.50-5.75)$ & 4.50 & $(3.00-5.00)$ & 4.75 & $(3.75-5.75)$ & 0.15 \\
\hline Amotivation & 1.00 & $(1.00-2.25)$ & 1.00 & $(1.00-2.00)$ & 1.25 & $(1.00-1.75)$ & 0.85 \\
\hline SDI & 12.12 & $(9.16-12.91)$ & 11.33 & $(9.75-13.25)$ & 11.45 & (10.37-13.79) & 1.0 \\
\hline \multicolumn{8}{|l|}{ Mood states } \\
\hline Tension & 3.0 & $(2.0-5.0)$ & 3.0 & $(2.0-6.0)$ & 2.0 & $(1.0-3.0)$ & 0.63 \\
\hline Depression & 1.0 & $(0.0-4.0)$ & 0.0 & $(0.0-3.0)$ & 0.0 & $(0.0-0.0)$ & 0.10 \\
\hline Anger & 0.0 & $(0.0-4.0)$ & 0.0 & $(0.0-0.0)$ & 0.0 & $(0.0-0.0)$ & 0.49 \\
\hline Vigour & 9.0 & $(8.0-11.0)$ & 11.0 & $(7.0-12.0)$ & 10.0 & $(8.0-13.0)$ & 0.53 \\
\hline Fatigue & 5.0 & $(3.0-8.0)$ & 8.0 & (3.0-10.0) & 5.0 & $(1.0-6.0)$ & 0.24 \\
\hline Confusion & 1.0 & $(0.0-3.0)$ & 1.0 & $(0.0-4.0)$ & 1.0 & $(0.0-2.0)$ & 0.77 \\
\hline
\end{tabular}

$\mathrm{T}$ - testing time, IM - intrinsic motivation, EM - extrinsic motivation, SDI - self-determination index 


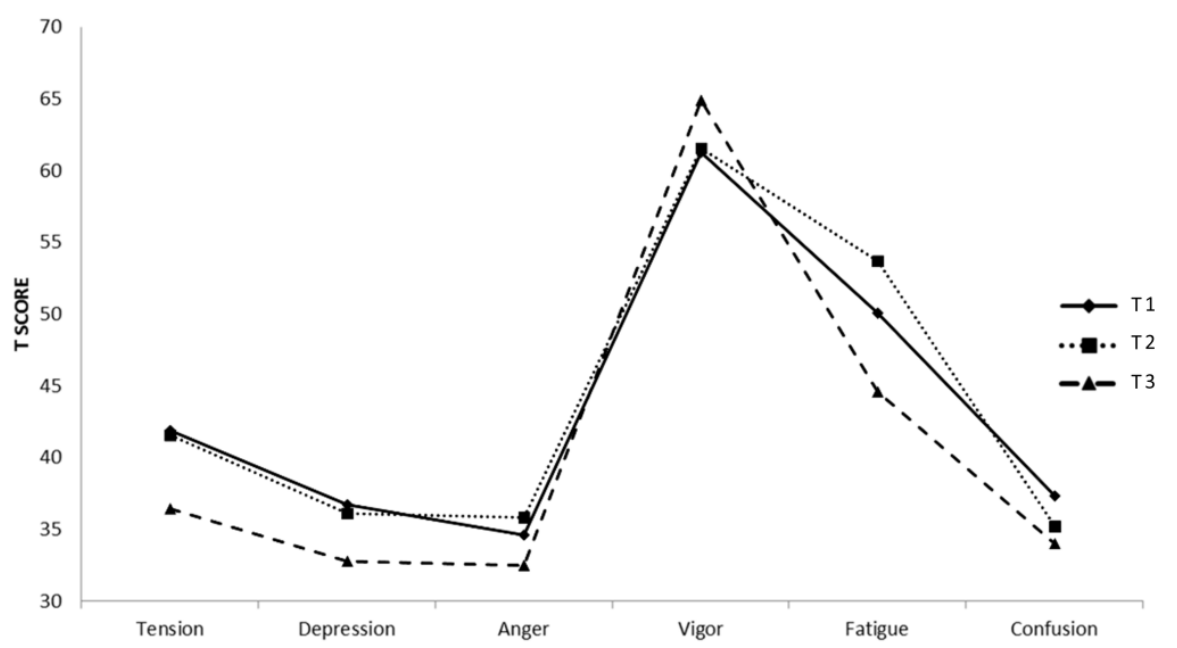

Figure 1. 'Iceberg profile' in the Paralympic swimmers during the testing times

Table 3. Scales of the dimensions 'General stress,' 'Sport stress,' 'General recovery,' and 'Sport recovery' in the Paralympic swimmers during the testing times

\begin{tabular}{|c|c|c|c|c|c|c|c|}
\hline \multirow{4}{*}{ RESTQ-Sport } & $\mathrm{T} 1$ & $\mathrm{~T} 2$ & T3 & \multirow{4}{*}{$\begin{array}{c}\text { Friedman } \\
\text { ( } p \text { value) }\end{array}$} & \multicolumn{3}{|c|}{ Wilcoxon test } \\
\hline & & & & & T1 & T1 & $\mathrm{T} 2$ \\
\hline & Median (25-75\%) & Median (25-75\%) & Median (25-75\%) & & vs. & vs. & vs. \\
\hline & & & & & T2 & T3 & $\mathrm{T} 3$ \\
\hline
\end{tabular}

General stress

1. General stress

2. Emotional stress

3. Social stress

4. Conflicts/pressure

5. Fatigue

6. Lack of energy

7. Somatic complaints

Sport stress

13. Disturbed breaks

14. Emotional exhaustion

15. Injuries

$\begin{array}{llllllll}1.00 & (0.25-1.50) & 0.75 & (0.25-1.25) & 0.75 & (0.00-3.00) & 0.83 \\ 0.75 & (0.50-1.75) & 1.00 & (0.50-1.50) & 0.75 & (0.25-1.75) & 0.90 \\ 0.50 & (0.25-1.00) & 1.00 & (0.00-1.25) & 1.00 & (0.00-3.00) & 0.78 \\ 3.00 & (2.25-3.75) & 2.25 & (1.75-3.25) & 1.75 & (1.50-3.00) & 0.01^{*} \\ 3.25 & (2.00-4.00) & 2.25 & (1.25-3.50) & 2.25 & (1.25-2.50) & <0.01^{*} \\ 1.00 & (0.75-1.75) & 0.75 & (0.50-2.25) & 1.00 & (0.00-3.25) & 0.78 \\ 1.50 & (1.00-2.75) & 1.50 & (0.75-2.50) & 1.50 & (0.50-2.25) & 0.42 \\ & & & & & & \\ 2.25 & (1.00-3.25) & 2.00 & (0.25-3.25) & 1.50 & (0.25-2.50) & 0.14 \\ 1.50 & (1.00-2.50) & 1.25 & (0.25-2.00) & 1.50 & (0.00-2.00) & 0.47 \\ 3.00 & (2.25-3.75) & 2.25 & (2.00-3.75) & 2.25 & (0.75-3.00) & 0.16\end{array}$

General recovery

8. Success

9. Social relaxation

10. Somatic relaxation

11. General well-being

12. Sleep quality

$\begin{array}{llllllll}3.50 & (2.75-4.50) & 4.00 & (3.25-4.75) & 3.75 & (2.00-5.00) & 0.59 \\ 4.25 & (4.00-4.75) & 5.00 & (4.25-5.50) & 4.25 & (2.25-5.50) & 0.30 \\ 3.75 & (2.75-4.25) & 4.00 & (2.25-4.50) & 4.25 & (2.25-4.75) & 0.85 \\ 4.25 & (3.50-5.00) & 5.00 & (4.00-5.25) & 5.00 & (1.50-5.25) & 0.72 \\ 4.00 & (2.50-4.00) & 4.50 & (3.00-4.50) & 4.00 & (1.00-5.00) & 0.18\end{array}$

Sport recovery

16. Being in shape

$\begin{array}{lllllll}4.00 & (3.25-4.50) & 4.25 & (3.00-4.75) & 4.25 & (2.25-5.50) & 0.83\end{array}$

17. Personal accomplishment

18. Self-efficacy

$4.00 \quad(3.00-5.50) \quad 4.25$

$(3.75-4.75) \quad 4.00 \quad(3.75-5.25)$

0.51

$4.25 \quad(3.50-5.25) \quad 4.75 \quad(3.00-5.25) \quad 4.75 \quad(3.00-5.50)$

$5.50 \quad(4.00-5.50) \quad 5.00 \quad(4.00-5.25) \quad 5.00 \quad(3.25-6.00)$

$2.10 \quad(1.30-3.00) \quad 2.74 \quad(1.77-3.73) \quad 2.14 \quad(0.00-4.50)$
19. Self-regulation

TRSS

RESTQ ${ }^{*} p<0.05$ 
$p<0.01]$. The athletes presented differences in conflicts/pressure values in T1 $>\mathrm{T} 2(p=0.03)$ and $\mathrm{T} 1>\mathrm{T} 3$ $(p<0.01)$, and in fatigue in T1>T2 $(p=0.05)$ and $\mathrm{T} 1>\mathrm{T} 3(p=0.01)$. No statistically significant changes were found between TRSS values $\left[\chi^{2}(2 . N=11)=\right.$ $0.72 ; p=0.69]$.

Spearman's rank-order correlation determined relationships between the variables of interest. In T1, there was a positive correlation between the number of 'worse than normal' responses (part B) and fatigue score present in both BRUMS $(r=0.67 ; p=0.02)$ and RESTQ-Sport $(r=0.70 ; p=0.01)$.

On the other hand, a negative correlation was observed with the number of 'worse than normal' responses (part B) and vigour (BRUMS) in T2 $(r=-0.63$; $p=0.04)$.

Motivation had a negative correlation with fatigue in T1 ( $r=-0.71 ; p=0.01)$. In addition, our study demonstrates a negative correlation between T1 internal training load and the conflicts/pressure RESTQ-Sport subscale $(r=-0.76 ; p<0.01)$.

\section{Discussion}

The presented study analysed multi-parameter variables (internal training load, motivation levels, mood states, stress, and recovery) during the training cycle of Paralympic swimmers before the Rio 2016 Paralympic Games. Our results confirm the hypothesis in relation to differences in perceived training load and psychobiological aspects of the Paralympic athletes before the Rio 2016 Paralympic Games.

Considering the development of Paralympic sport, studies have investigated performance improvement through technical, biomechanical, and physiological parameters [3, 20] . In addition, some papers have suggested that psychobiological evaluation is a useful tool that may improve the understanding of athletes with impairments in the context of the perceived barriers and facilitators to sport (to avoid possible dropouts) and performance [21, 22].

Internal load monitoring is one simple way to establish the individual training stress, and sRPE gives information about some of the components in different exercise stimuli, such as steady-state or interval training, allowing coaches to evaluate if the athlete is coping or not coping with the external training loads prescribed in swimming training [23].

In the present study, internal training load showed high values at the beginning of the training cycle, and the perceived training load decreased before the Rio 2016 Paralympic Games (T1>T3; T2>T3).
In swimming, periodization is often used, which includes a general period (training is focused on volume) and a specific period (training intensity increases). In the competitive and tapering periods, training volume decreases to allow for sufficient time for rest and recovery. The proper distribution of the training load during the competitive season may have been an important factor for the Brazilian Paralympic swimmers, who obtained positive results $(4$ gold, 7 silver, and 8 bronze medals) in the Rio 2016 Paralympic Games.

Swimming is a sport that emphasizes high frequency and volume of training [21] and can lead to athletes exceeding their adaptation threshold. In relation to psychological indicators, the motivational level in athletes is an essential variable for athletic success. In the present study, the Paralympic swimmers presented a self-determined motivation profile, predominantly for the intrinsic motivational level, and this result corroborates other studies, showing that athletes with physical impairments tend to report high levels of intrinsic motivation [24]. This could be justified by coping strategies acquired by athletes because of their impairments; in addition, they may develop psychological skills (motivation) which can transfer to the sport [25].

The monitoring of mood state can be a valuable tool to improve the physical and psychological performance of athletes. In this study, there was not any difference between the dimensions evaluated in the BRUMS mood questionnaire during the testing times. However, we observed the 'iceberg profile,' representing positive mental health in the parathletes [26], and it is speculated that this may be related to the level of athlete aspirations, or competing at home with support (family and friends), possibly bettering their chances in competition.

Low scores of the negative dimensions (tension, depression, anger, fatigue, and confusion) and high scores of the positive dimension (vigour) to describe the intercommunication between multiple negative and positive mood states that affect training or athletic performance characterize this status. According to Martin et al. [27], athletes with impairments have typically reported 'iceberg mood profiles' and with some limitations, it is useful to evaluate the relationship between mood and performance.

Another tool to evaluate stress tolerance associated with the training process is the DALDA questionnaire [18]. However, the possible effect of sRPE and stress tolerance in sport is incipient. In this study, we observed a higher number of 'worse than normal' responses (T1>T3; T2>T3) in DALDA part B (stress symp- 
toms) in the testing times with the highest internal load. A study conducted by Moreira et al. [28] shows a significant increase in 'worse than normal' responses in DALDA part B for athletes with the highest average weekly training load (> $400 \mathrm{AU}$ ).

Despite this, we found no correlation between the training load and 'worse than normal' responses in the testing times evaluated in this study. However, during $\mathrm{T} 1$, a positive correlation was observed between the number of 'worse than normal' responses (part B) and the fatigue score present in both BRUMS ( $r=$ $0.67 ; p=0.02)$ and RESTQ-Sport $(r=0.70 ; p=0.01)$. Studies have shown that fatigue correlates with changes in stress during the training period [18].

On the other hand, there was a negative correlation between the number of 'worse than normal' responses (part B) and vigour (BRUMS) in T2 $(r=-0.63 ; p=0.04)$, indicating that variations in stress symptoms in Paralympic swimmers can be correlated with mood state.

In the RESTQ-Sport analysis, significant differences were observed between the subscales of conflicts/pressure and fatigue in T1>T2 and T1>T3. An increase in these scores was expected because the training factors directly influence them [29]. In our study, motivation had a negative correlation with fatigue in T1 $(r=-0.71 ; p=0.01)$, corroborating the review study by Halson [4], which suggested that athletes in fatigue condition might also demonstrate lack of motivation.

In addition, our study demonstrates a negative correlation between $\mathrm{T} 1$ internal training load and the RESTQ-Sport subscale of conflicts/pressure ( $r=-0.76$; $p<0.01$ ). This outcome does not support the results found in the study conducted by Jürimäe et al. [30], where a greater training volume of athletes was correlated with the scores of conflicts/pressure $(r=0.63)$ in the heavy training period. Although T1 showed higher values in internal load training, the training periodization proposed by Brazilian Paralympic coaches can explain this negative correlation. At the start of the season, they could have used a periodization method representing a specific block of training designed to accomplish a particular goal, not necessarily corresponding to an increase in the swimming training volume.

No statistically significant changes were noted between the values of TRSS in the testing times. Thus, with some limitations, we verified that the RESTQSport scales reflected the state of stress and recovery of the Paralympic swimmers.

In the present study, the internal training load seems to influence the psychobiological demands of
Paralympic swimmers in a competitive season. These results reinforce the importance of monitoring psychobiological factors in sports, as the athletes' inability to recover from overtraining may be accompanied by an increase in social and psychological stress.

Fluctuations in behavioural factors during the competitive season are likely to occur owing to training, performance, and expected results. The use of questionnaires is practical and allows to promptly collect large amounts of information at a relatively low cost.

As the study shows, a long-term period of collecting regular data by means of questionnaires/diaries would provide valuable information. This practical application would allow for a simultaneous collection of data from athletes outside the laboratory environment, facilitating the monitoring of variables that determine the athletes' performance during the training period.

A limitation of the study was the lack of physical performance assessment in the athletes during the evaluated training weeks. Regarding the experimental design of the study, the future investigations of the variables presented here can be influenced in accordance with the structure, duration, and intensity of the training program, as well as individual characteristics of parathletes considering their health condition.

Therefore, the limitations should be considered in the analysis and interpretation of the results presented. Other variables, such as the sample size, injuries/pain rate, and external training loads, were not followed. One feature to be taken into account was the heterogeneity of the sample athletes with regard to the functional impairments and sports classifications. These characteristics, inherent in Paralympic sport, should be considered in future studies on psychobiological factors in Paralympic athletes.

\section{Conclusions}

During the training cycle (between T1, T2, and T3) of Brazilian Paralympic swimmers, the internal training load (measured by sRPE) decreased from T1 to T3; symptoms of stress (measured by the DALDA questionnaire) in the testing times were lowest with the lowest internal load in T3, and the scales of conflicts/ pressure and fatigue of the 'General stress' dimension (measured by RESTQ-Sport) were highest in T1. The results indicate that the monitoring of multi-parameter data inherent in the training cycle may explain the psychobiological aspects of Paralympic swimmers. In addition, as a practical implication of this study, 
the psychobiological variables can be evaluated by subjective instruments, and in conjunction with other indicators, provide important information for coaches and athletes to meet the specific demands of impaired athletes to achieve better performance in the Paralympic sports.

\section{Acknowledgments}

The authors express their gratitude to the Centro de Estudos em Psicobiologia e Exercício (CEPE), the Conselho Nacional de Desenvolvimento Científico e Tecnológico (CNPq), Coordenação de Aperfeiçoamento de Pessoal de Nível Superior (CAPES) - Finance Code 001, the Fundação de Amparo à Pesquisa do Estado de Minas Gerais (FAPEMIG), the Comitê Paralímpico Brasileiro (CPB), and the Academia Paralímpica Brasileira (APB). We also thank all the Brazilian Paralympic swimmers and coaches who participated in this study.

\section{Disclosure statement}

No author has any financial interest or received any financial benefit from this research.

\section{Conflict of interest}

The authors state no conflict of interest.

\section{References}

1. Willis S, Schleier A, De Luigi AJ. Adaptive water sports. In: De Luigi AJ (ed.), Adaptive sports medicine. A clinical guide. Cham: Springer; 2018; 227-243.

2. IPC Swimming. Swimming classification: manual. IPC Swimming; 2005.

3. Fulton SK, Pyne DB, Hopkins WG, Burkett B. Training characteristics of Paralympic swimmers. J Strength Cond Res. 2010;24(2):471-478; doi: 10.1519/JSC.0b013e31 81c09a9e.

4. Halson SL. Monitoring training load to understand fatigue in athletes. Sports Med. 2014;44(Suppl. 2):139147; doi: 10.1007/s40279-014-0253-z.

5. Martin JJ. Determinants of elite disability sport performance. Kinesiol Rev. 2015;4(1):91-98; doi: 10.1123/ kr.2014-0082.

6. Kreher JB, Schwartz JB. Overtraining syndrome: a practical guide. Sports Health. 2012;4(2):128-138; doi: 10.1177/1941738111434406.

7. Mageau GA, Vallerand RJ. The coach-athlete relationship: a motivational model. J Sports Sci. 2003;21(11): 883-904; doi: 10.1080/0264041031000140374.

8. Stefanek KA, Peters HJ. Motivation in sport: theory and application. In: Cox WM, Klinger E (eds.), Handbook of motivational counseling. Chichester: WileyBlackwell; 2011; 415-435.
9. Samulski D, Noce F. Psychological profile of Brazilian Paralympic athletes [in Portuguese]. Rev Bras Med Esporte. 2002;8(4):157-166; doi: 10.1590/S1517-869 22002000400005

10. Ryan RM, Deci EL. Self-determination theory and the facilitation of intrinsic motivation, social development, and well-being. Am Psychol. 2000;55(1):68-78; doi: 10.1037//0003-066X.55.1.68.

11. Gillet N, Vallerand RJ, Paty B. Situational motivational profiles and performance with elite performers. J Appl Soc Psychol. 2013;43(6):1200-1210; doi: 10.1111/jasp. 12083.

12. Sabato TM, Walch TJ, Caine DJ. The elite young athlete: strategies to ensure physical and emotional health. Open Access J Sports Med. 2016;7:99-113; doi: 10.2147/ OAJSM.S96821.

13. Foster C, Florhaug JA, Franklin J, Gottschall L, Hrovatin LA, Parker S, et al. A new approach to monitoring exercise training. J Strength Cond Res. 2001;15(1): 109-115; doi: 10.1519/00124278-200102000-00019.

14. Bara Filho M, Andrade D, Miranda R, Núñez JL, Martín-Albó J, Ribas PR. Preliminary validation of a Brazilian version of the Sport Motivation Scale. Univ Psychol. 2011;10(2):557-566; doi: 10.11144/Javeriana. upsy10-2.pvbv.

15. Chantal Y, Robin P, Vernat J-P, Bernache-Assollant I. Motivation, sportspersonship, and athletic aggression: a mediational analysis. Psychol Sport Exerc. 2005;6(2): 233-249; doi: 10.1016/j.psychsport.2003.10.010.

16. Rohlfs I, Rotta T, Andrade A, Terry P, Krebs R, Carvalho T. The Brunel of Mood Scale (BRUMS): instrument for detection of modified mood states in adolescents and adults athletes and non athletes. FIEP Bulletin. 2005;75:281-284.

17. Moreira A, Cavazzoni PB. Monitoring training with the Portuguese versions of Wisconsin Upper Respiratory Symptom Survey-21 and Daily Analysis of Life Demands for Athletes [in Portuguese]. J Phys Educ. 2009;20(1):109-119; doi: 10.4025/reveducfis.v20i1.5289.

18. Robson-Ansley PJ, Gleeson M, Ansley L. Fatigue management in the preparation of Olympic athletes. J Sports Sci. 2009;27(13):1409-1420; doi: 10.1080/02 640410802702186.

19. Costa LOP, Samulski DM. Validation process of the Recovery-Stress Questionnaire for Athletes (RESTQSport) in Portuguese [in Portuguese]. Rev Bras Cienc Mov. 2005;13(1):79-86; doi: 10.18511/rbcm.v13i1.615.

20. Marszalek J, Gryko K, Prokopowicz G, Kosmol A, Mroz A, Morgulec-Adamowicz N, et al. The physiological response of athletes with impairments in wheelchair basketball game. Hum Mov. 2019;20(4):1-7; doi: 10.5114/hm.2019.84005.

21. González-Boto R, Salguero A, Tuero C, González-Gallego J, Márquez S. Monitoring the effects of training load changes on stress and recovery in swimmers. J Physiol Biochem. 2008;64(1):19-26; doi: 10.1007/ BF03168231. 
22. Denardin Cardoso V, De Castro Haiachi M, Reppold Filho AR, Araújo Gaya AC. Reasons for continuity of athletes in Brazilian Paralympic sport [in Portuguese]. Rev Iberoamericana Psicol Ejercicio Deporte. 2019; 14(1):8-11.

23. Wallace L, Coutts A, Bell J, Simpson N, Slattery K. Using session-RPE to monitor training load in swimmers. Strength Cond J. 2008;30(6):72-76; doi: 10.1519/SSC. 0b013e31818eed5f.

24. Perreault S, Vallerand RJ. A test of self-determination theory with wheelchair basketball players with and without disability. Adapt Phys Activ Q. 2007;24(4): 305-316; doi: 10.1123/apaq.24.4.305.

25. Cox RH, Davis RW. Psychological skills of elite wheelchair athletes. Palaestra. 1992;8(3):16-21.

26. Rodrigues DF, Silva A, Rosa JPP, Ruiz FS, Veríssimo AW, Winckler C, et al. Sleep quality and psychobiological aspects of Brazilian Paralympic athletes in the London 2012 pre-Paralympics period. Motriz Rev Educ Fis. 2015;21(2):168-176; doi: 10.1590/S1980-657420150 00200007.

27. Martin JJ, Malone LA, Hilyer JC. Personality and mood in women's Paralympic basketball champions. J Clin Sport Psychol. 2011;5(3):197-210; doi: 10.1123/ jcsp.5.3.197.

28. Moreira A, de Freitas CG, Nakamura FY, Aoki MS. Session RPE and stress tolerance in young volleyball and basketball players [in Portuguese]. Rev Bras Cineantropom Desempenho Hum. 2010;12(5):345-351; doi: 10.5007/1980-0037.2010v12n5p345.

29. Coutts AJ, Reaburn P, Piva TJ, Rowsell GJ. Monitoring for overreaching in rugby league players. Eur J Appl Physiol. 2007;99(3):313-324; doi: 10.1007/s00421006-0345-z.

30. Jürimäe J, Mäestu J, Purge P, Jürimäe T, Sööt T. Relations among heavy training stress, mood state, and performance for male junior rowers. Percept Mot Skills. 2002;95(2):520-526; doi: 10.2466/pms.2002.95.2.520. 